\title{
Climate change and its effects on farm workers
}

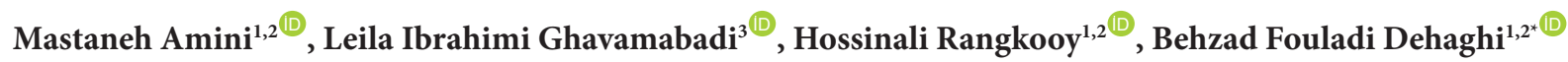 \\ ${ }^{1}$ Environmental Technologies Research Center, School of Public Health, Ahvaz Jundishapur University of Medical Sciences, Ahvaz, \\ Iran \\ ${ }^{2}$ Department of Occupational Health Engineering, School of Public Health, Ahvaz Jundishapur University of Medical Sciences, Iran \\ ${ }^{3}$ Department of Environmental Management-HSE, Ahvaz Branch, Islamic Azad University, Ahvaz, Iran
}

\begin{abstract}
Background: One of the biggest global occupational threats, especially in the outdoor workplace, is climate change and global warming, as workers are exposed to the heat stress leading to reduced performance. The aim of this study was to investigate the effect of workplace climate on labor productivity index in the agricultural sector.

Methods: In this study, data related to environmental variables of 215 synoptic meteorological stations in Khuzestan province were collected from three climatic regions (hot, mild, and cold). Using MATLAB R 2018b mathematical software based on ASHRAE/ISO7730 standard values by designing some scenarios, predicted mean vote (PMV) index, and then, labor productivity index (P) were estimated. The data were analyzed using SPSS version 25 software.

Results: The results showed that in the hot regions, there is a significant inverse relationship between $\mathrm{P}$ index and the main environmental variables (ta, tr, pa). In the cold regions, increasing the amount of ta and tr in light and medium workload improved the P index, but for heavy workload, it reduced productivity, and the most effective factor was increasing air vapor pressure. In the mild regions, the most effective factor in productivity was air vapor pressure. In addition, the results of Spearman's correlation coefficient showed that PMV index has a direct and significant relationship with P index. Conclusion: Regarding the increasing trend of climate change and its effect on the desired thermal comfort and productivity, well structure and planning is needed to manage farm workers health. Keywords: Workplace, Climate conditions, Labor, Agricultural Citation: Amini M, Ibrahimi Ghavamabadi L, Rangkooy H, Fouladi Dehaghi B. Climate change and its effects on farm workers. Environmental Health Engineering and Management Journal 2021; 8(3): 179-185. doi: 10.34172/EHEM.2020.21.
\end{abstract}

\section{Article History:}

Received: 18 February 2021

Accepted: 21 April 2021

ePublished: 27 July 2021
*Correspondence to:

Behzad Fouladi Dehaghi,

Email: bdehaghi@gmail.com

\section{Introduction}

Iranian agricultural sector is divided into five main subsectors: Agriculture, animal husbandry and hunting, forestry, fishing, and agricultural services. According to the results of the census all over Iran in 2016, the share of employees in the agricultural sector in terms of urban and rural areas is $16.1 \%$ of the whole population, mostly in rural areas (1). Unfortunately, due to climate change and the increased exposure of workers to heat, occupational health risks have increased and the workers' ability and productivity have decreased (2). Especially in the manufacturing and agricultural sectors of developing countries, it has a negative impact on human resources productivity (3). In the report of the US National Aeronautics and Space Administration (NASA) entitled Climate Change and Global Warning in 2016, the first six months of this year set the record for the warmest temperature in the world $(4,5)$. Therefore, workplace weather conditions are considered as important physical factors affecting the mental and physical performance of individuals $(6,7)$. Farm workers are among the people who usually work between 8 to 10 hours a day, outside $(8,9)$ and are exposed to higher levels of ambient temperature that ultimately influences their productivity as well as economic growth in a negative manner $(10,11)$. Numerous epidemiological studies have shown that high temperatures increase mortality and health complications (12-14). On the other hand, the study of Yi et al showed that heat stress increases about $33 \%$ per $1^{\circ} \mathrm{C}$ increase in wet bulb globe temperature (WBGT) index (15), but unfortunately, few studies have estimated the economic costs of climate change (16). In developing countries, labor is considered as the most important factor of production, so the possible impact of climate change on this index is an important concern (17). Zander et al, estimated an 11 to $27 \%$ reduction in productivity by the end of the $21^{\text {st }}$ 
century in warmer regions of the world (such as Asia) (18). In another study, the rate of productivity decline in various occupations of agricultural sectors in the summer due to heat was shown to be $69.3 \%$ per hour (19). In another study, it was shown that for heavy load work, productivity is reduced by $20 \%$ to $30 \%$ (20). On the other hand, raising temperatures may increase labor productivity in cold regions (21). Among climatic phenomena, extreme temperatures and heat waves have the greatest effects on individuals $(22,23)$. Using the thermal comfort index, this study was conducted to show which climatic factors in each region affects the labor productivity and how it can be improved. This study, due to the abundance of employees in the agricultural sector, aimed to determine the effects of workplace climate on human resources productivity, in three climatic regions (cold, hot, and mild) of Iran based on the available data in 2016.

\section{Materials and Methods \\ Study area}

Khuzestan province is located in the southwest of Iran $\left(31.4360^{\circ} \mathrm{N}, 49.0413^{\circ} \mathrm{E}\right)$. The region is located in a hot semi-arid climate zone and most meteorology stations have recorded a maximum air temperature of $50^{\circ} \mathrm{C}$ in recent summer. This region is divided into three different climatic classifications and a meteorological station was selected from each of them.

\section{Study design}

The present cross-sectional analytical study, was conducted by the initial review of the source of information and statistics of the Meteorological Organization (24); then, 215 available synoptic stations were determined based on the Morgan's table and Cochran's calculation formula. The condition for selecting these one-year synoptic meteorological stations was access to atmospheric information required to calculate the predicted mean vote (PMV) index in accordance with the latest labor productivity index reported in the agricultural sector by the National Productivity Organization (NPO) (25).

\section{Determining the predicted mean vote index}

The PMV index was used to simultaneously evaluate thermal comfort criteria such as climate variables, clothing, and type of activity (26). In this study, to calculate the PMV, index of environmental variables including air temperature $\left(\mathrm{t}_{\mathrm{a}}\right)$ and mean radiant temperature $\left(\mathrm{t}_{\mathrm{r}}\right)$ in ${ }^{\circ} \mathrm{C}$, air vapor pressure $\left(\mathrm{P}_{\mathrm{a}}\right)$ in $\mathrm{mm} \mathrm{Hg}$, and relative air velocity $\left(\mathrm{v}_{\mathrm{a}}\right)$ in $\mathrm{m} / \mathrm{s}$ were collected and coverage information were estimated in terms of Clo (Icl) $(27,28)$ and activity rate (M) in $\mathrm{w} / \mathrm{m}^{2}(27,29)$. According to the recommendation of ASHRAE/ISO 7730 standard, spectrum $-1<\mathrm{PMV}<1$ was used as shown in Table $1(27,30)$. Also, Figure 1 shows the ASHRAE thermal sensation scale based on the PMV scale.
Table 1. PMV and $P$ indices in the range of thermal comfort for all three types of light, medium, and heavy activities

\begin{tabular}{lccc}
\hline PMV & $\mathbf{P}_{\mathbf{I}}$ & $\mathbf{P}_{\mathbf{m}}$ & $\mathbf{P}_{\mathbf{h}}$ \\
\hline 1 & 104.64 & 105.36 & 115.08 \\
0 & 102 & 102 & 83 \\
-1 & 103.04 & 102.98 & 69.98 \\
\hline
\end{tabular}

\begin{tabular}{|ccccccc}
-3 & -2 & -1 & 0 & 1 & 2 & 3 \\
\hline cold & cool & $\begin{array}{c}\text { slightly } \\
\text { cool }\end{array}$ & Neutral & $\begin{array}{c}\text { slightly } \\
\text { warm }\end{array}$ & warm & hot
\end{tabular}

(b)

Figure 1. ASHRAE thermal sensation scale based on the PMV scale (28).

\section{Assumptions of environmental study parameters}

Kjellstrom et al estimated that the WBGT level in the outdoor environment is approximately $3^{\circ} \mathrm{C}$ warmer than the indoor environment (31). Therefore, in this study, the parameter of the mean annual maximum temperature in each synoptic meteorological station was used as mean radiant temperature $\left(\mathrm{t}_{\mathrm{r}}=\mathrm{t}_{\mathrm{a} \text { max }},{ }^{\circ} \mathrm{C}\right)$ to be closer to the more realistic value of this parameter. To provide thermal comfort, the relative humidity average of $50 \%$ and the air velocity of $0.5 \mathrm{~m} / \mathrm{s}$, which indicates its average for various outdoor works, were considered.

\section{Assumptions of individual study parameters}

In this study, the coefficient of insufficiency of workers' clothing is equal to 0.75 to investigate environmental variables affecting their productivity (31). In this research, three types of whole-body work at three levels of light, medium, and heavy workloads $\left(125,190\right.$, and $280 \mathrm{~W} / \mathrm{m}^{2}$, respectively) were used in the calculations (Figure 2).

\section{Calculation of labor productivity index}

$\mathrm{P}$ index was calculated using the relevant equations (32). The scenarios in all three climatic regions were explored based on the main data as input, according to Table 2, using MATLAB R 2018b software. The study procedure for each scenario of the desired climatic region is shown in Figure 2. The scenarios for calculating PMV and P indices for all three hot, cold, and mild regions are as follows:

First model: Constant air temperature and variable vapor pressure

Second model: Variable air temperature and constant vapor pressure

Third model: Variable air temperature and variable vapor pressure

Finally, for each climate region, the comparison of human productivity index in three-scenario models with human productivity index in the range of thermal comfort (P threshold) was done according to Table 3 and the effect of environmental parameters was investigated according to 
Figure 3. Finally, the data were described using descriptive statistics methods including frequency, mean, and standard deviation. In the inferential statistics section, due to the non-normality of the data, to compare the average productivity of human resources in the three regions of cold, hot, and mild, Kruskal-Wallis and Dan-Bonferroni tests were applied and to examine the relationship between research variables, Spearman's correlation coefficient was used. Data were analyzed using SPSS version 25 software. Statistical significant level was considered at $P=0.05$. The study procedure for each scenario of the desired climatic region is shown in Figure 2.

\section{Results}

Among 215 meteorological synoptic stations and according to the Köppen-Geiger classification (33), stations with an average annual temperature above $18^{\circ} \mathrm{C}$ were considered as hot climate regions (74 stations), from 16 to $18^{\circ} \mathrm{C}$ as mild regions (35 stations), and temperatures below $16^{\circ} \mathrm{C}$ as cold regions (106 stations) $(31,34)$. Findings are presented in two parts: Calculation of equations of research indicators and statistical analysis. Initially, according to Table 1, the values of PMV index and labor productivity index in the range of thermal comfort for all three types of light $\left(\mathrm{M}<125 \mathrm{~W} / \mathrm{m}^{2}\right)$, medium $(125<\mathrm{M}$ $\left.<190 \mathrm{~W} / \mathrm{m}^{2}\right)$, and heavy $\left(\mathrm{M}>190 \mathrm{~W} / \mathrm{m}^{2}\right)$ activities $\left(\mathrm{P}_{\mathrm{l}}\right.$, $\left.\mathrm{P}_{\mathrm{m}}, \mathrm{P}_{\mathrm{h}}\right)$, were calculated and became the criteria of action. Table 3 shows that in all three models of the hot regions, the human productivity index for heavy activities is more significant than the amount related to the thermal comfort range. In addition, Table 4 shows that in the cold regions, due to cold weather and air vapor pressure, especially in light and medium activities, manpower productivity has a steady trend. In addition, in these regions, in the case of medium activities, manpower productivity is maintained within the threshold of its thermal comfort, and in the case of heavy activities, increasing the air vapor pressure

Table 2. Input data for calculating PMV and P indices by scenario in each climatic region

\begin{tabular}{|c|c|c|c|}
\hline Step & \multicolumn{2}{|c|}{ IN PUT } & OUT PUT \\
\hline 1 & $\begin{array}{l}\text { Main data } \\
\text { Assumptions }\end{array}$ & $\begin{array}{c}\mathrm{t}_{\mathrm{r}^{\prime}} \mathrm{t}_{\mathrm{a}^{\prime}} \mathrm{p}_{\mathrm{a}} \\
\mathrm{V}_{\mathrm{a}^{\prime}} \mathrm{M}, \mathrm{I}_{\mathrm{clo}}\end{array}$ & $\begin{array}{l}\text { PMV }_{1} \\
\text { PMV }_{m} \\
\text { PMV }_{b}\end{array}$ \\
\hline 2 & & & $\begin{array}{l}P_{1} \\
P_{m} \\
P_{h}\end{array}$ \\
\hline
\end{tabular}

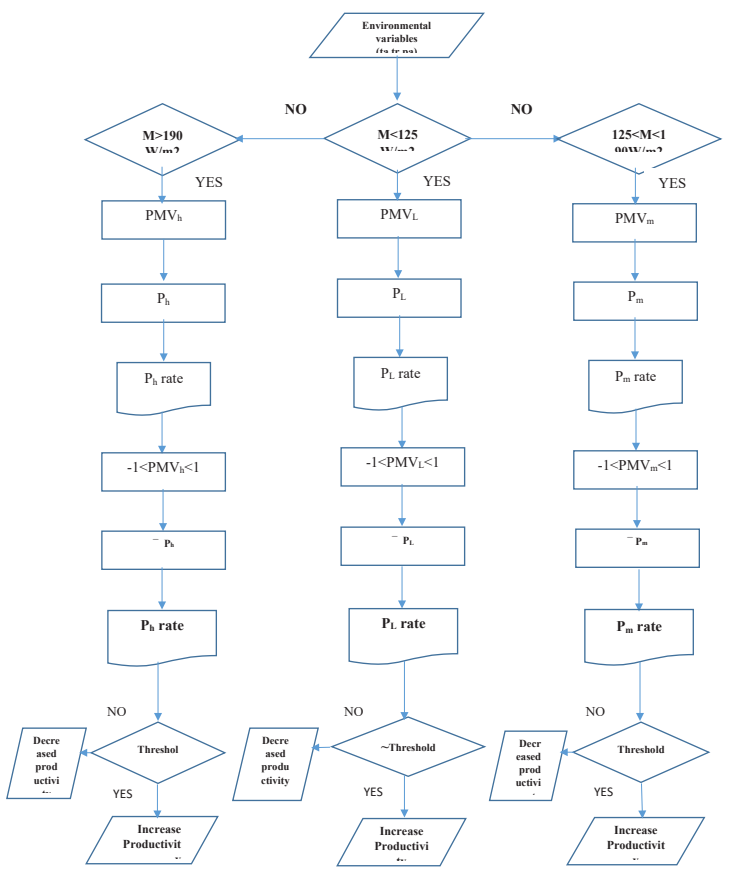

Figure 2. Procedures of the study.

reduces the human resources productivity index. Table 5 shows that in the mild regions, the productivity of manpower for light and medium activities is close to the threshold of thermal comfort, but due to the workload and heavy activities, the labor productivity index is decreased; in other words, it reduces the productivity of individuals. In mild climates, due to the stability of the trend of temperature changes, the only scenario was the first model. The diagrams in Figure 3 show and compare the results of the above-mentioned calculations.

\section{Statistical analysis}

In examining the relationship between environmental factors and $\mathrm{P}$ index, the average manpower productivity index in the hot regions was 131.92, in the mild regions was 112.73 , and in the cold regions was 105.01, which can be interpreted in terms of thermal comfort threshold. The results of correlation calculation which are presented in Figure 4 show a strong $\left(\mathrm{R}^{2}=0.98\right)$ and significant $(P<$ $0.05)$ relationship between $t_{a}, t_{r}$, and $P$ index in the cold regions, but the relationship between $\mathrm{p}_{\mathrm{a}}$ and $\mathrm{P}$ index in these regions is not strong $\left(\mathrm{R}^{2}=0.18\right)$. In the hot regions, all three main environmental variables have a strong $\left(\mathrm{R}^{2}\right.$

Table 3. Comparison of labor productivity index in three scenario models with thermal comfort range in the hot regions

\begin{tabular}{|c|c|c|c|c|c|c|}
\hline Scenario & $\mathbf{P}_{1}$ & Comfort & $\mathbf{P}_{\mathrm{m}}$ & Comfort & $\mathbf{P}_{\mathrm{h}}$ & Comfort \\
\hline $\begin{array}{l}\text { Constant air temperature, variable vapor } \\
\text { pressure }\end{array}$ & 103.04 & 104.64 & 111.02 & 105.36 & 272.59 & 115.08 \\
\hline $\begin{array}{l}\text { Variable air temperature, constant vapor } \\
\text { pressure }\end{array}$ & 102 & 102 & 103.48 & 102 & 199.36 & 115.08 \\
\hline $\begin{array}{l}\text { Variable air temperature, variable vapor } \\
\text { pressure }\end{array}$ & 102.27 & 103.04 & 103.29 & 102 & 177.09 & 115.08 \\
\hline
\end{tabular}



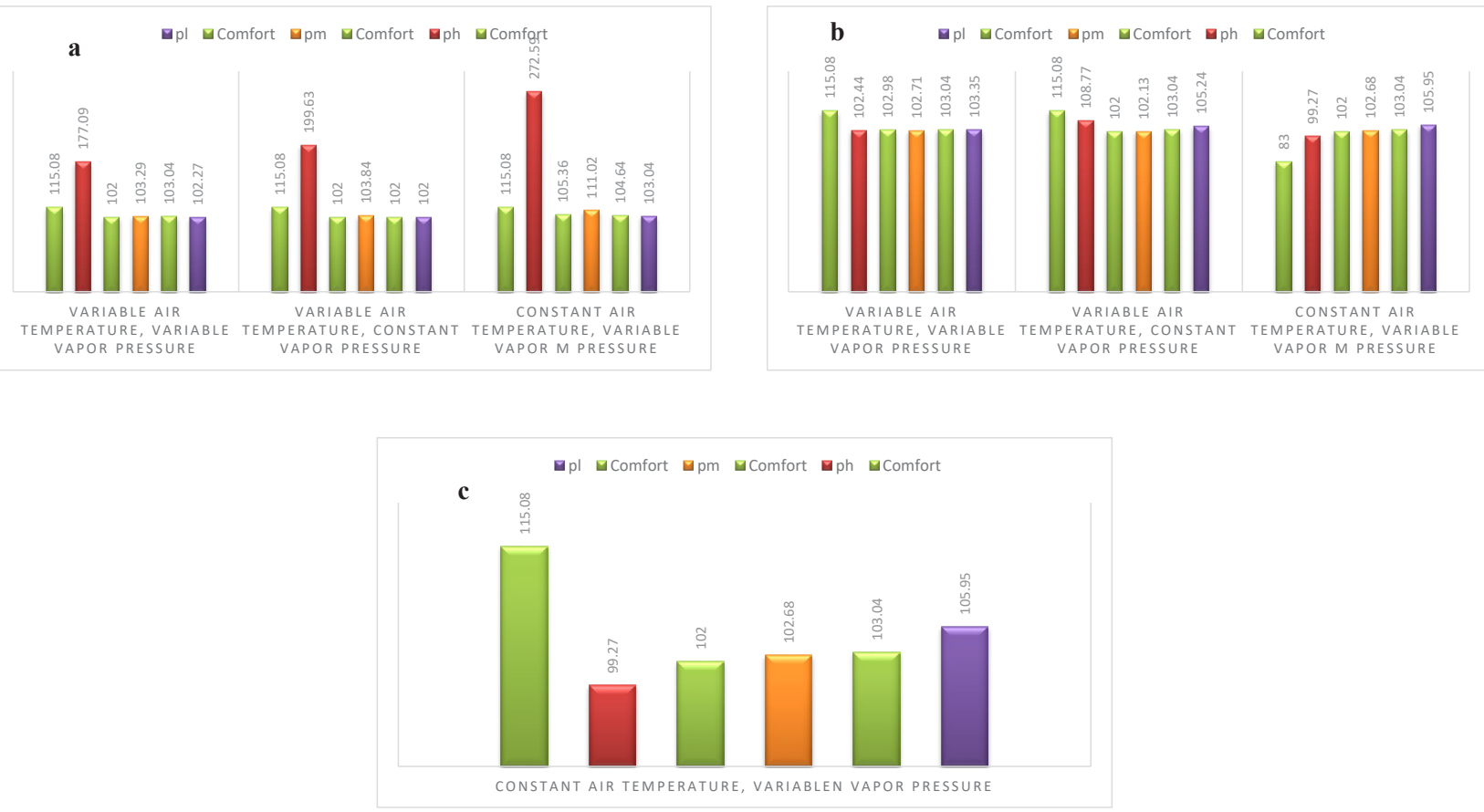

Figure 3 . Comparison of the results of climate change scenarios affecting the productivity of agricultural labor at three levels of work (light, medium, and heavy) in a) Hot climate regions, b) Cold climate regions, c) Mild climate regions with threshold of thermal comfort.

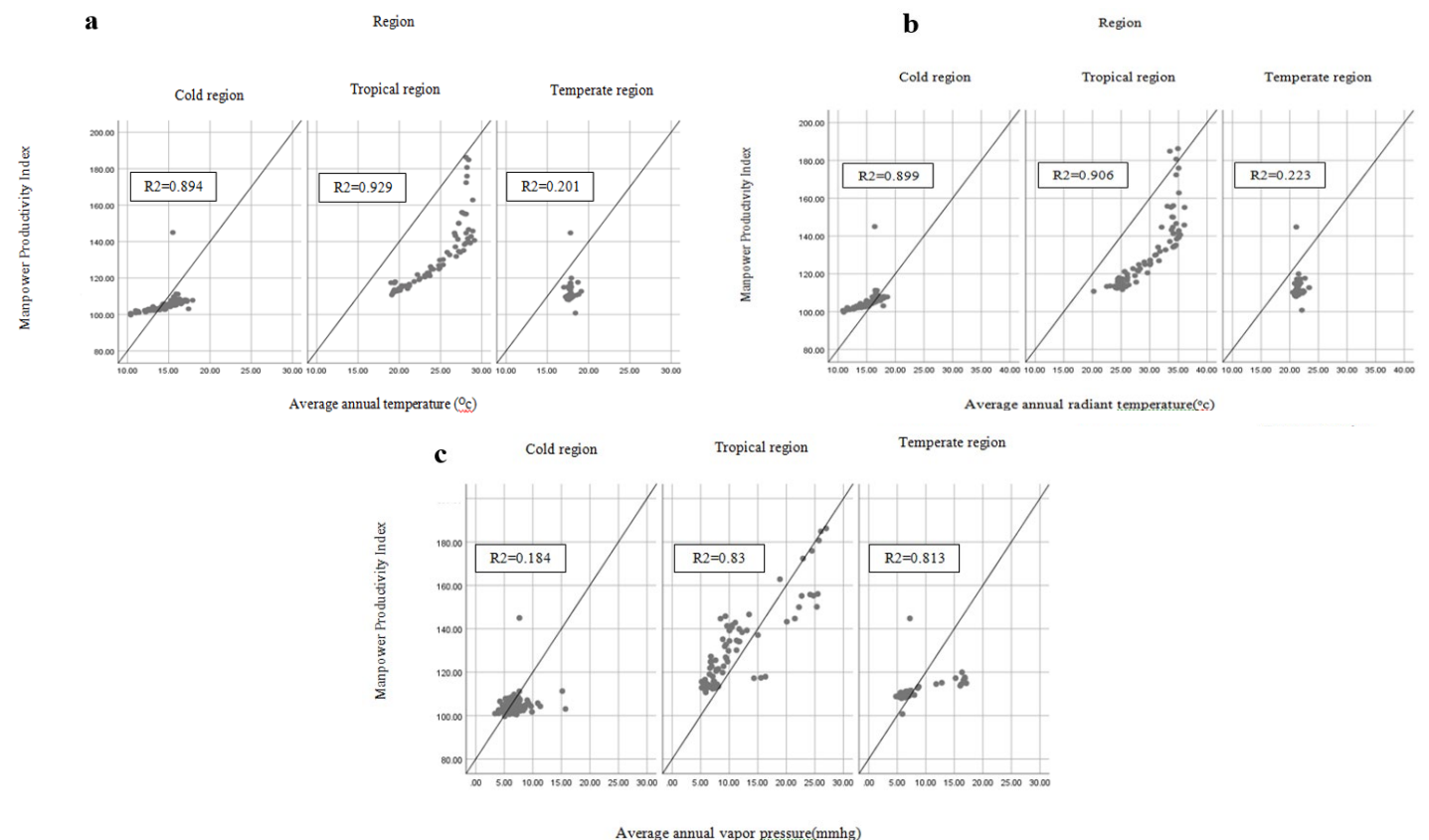

Figure 4 . The results of the correlation test of the main environmental variables with the manpower productivity index in the three climatic regions; a) The average annual temperature, b) The average radiant temperature, c) The air vapor pressure.

$=0.92)$ and significant correlation $(P<0.05)$ with the $\mathrm{P}$ index. In the mild regions, only the air vapor pressure has a strong $\left(\mathrm{R}^{2}=0.81\right)$ and significant correlation $(P<0.05)$ with the $\mathrm{P}$ index. The results showed a strong correlation $\left(\mathrm{R}^{2}>0.9\right.$ in the cold and hot regions, $\mathrm{R}^{2}>0.8$ in the mild regions) between the PMV index at three levels of workload (light, medium, and heavy) and manpower productivity index with a significant coefficient $(P=$ 0.001). According to the comparison criterion of this study, the average total productivity obtained in the three climatic regions (116.55) with the calculated average manpower productivity in the comfort zone based on the desired values of the index (PMV) was 98.68, and also, the P index of the NPO is equal to 121 , indicating that 
Table 4. Comparison of labor productivity index in three scenario models with thermal comfort range in the cold regions

\begin{tabular}{lcccccc}
\hline Scenario & $\mathbf{P}_{\mathbf{I}}$ & Comfort & $\mathbf{P}_{\mathbf{m}}$ & Comfort & $\mathbf{P}_{\mathbf{h}}$ & Comfort \\
\hline $\begin{array}{l}\text { Constant air temperature, variable vapor } \\
\text { pressure }\end{array}$ & 105.95 & 103.04 & 102.68 & 102 & 99.27 & 83 \\
$\begin{array}{l}\text { Variable air temperature, constant vapor } \\
\text { pressure }\end{array}$ & 105.24 & 103.04 & 102.13 & 102 & 108.77 & 115.08 \\
\hline \begin{tabular}{l} 
Variable air temperature, variable vapor pressure \\
\hline
\end{tabular} & 103.35 & 103.04 & 102.71 & 102.98 & 102.44 & 115.08 \\
\hline
\end{tabular}

Table 5. Comparison of labor productivity index in the scenario model with the range of thermal comfort in the mild regions

\begin{tabular}{lcccccc}
\hline Scenario & $\mathbf{P}_{\mathbf{l}}$ & Comfort & $\mathbf{P}_{\mathbf{m}}$ & Comfort & $\mathbf{P}_{\mathbf{h}}$ & Comfort \\
\hline $\begin{array}{l}\text { Constant air temperature, variable vapor } \\
\text { pressure }\end{array}$ & 103.23 & 103.04 & 101.90 & 102 & 135.60 & 115.08 \\
\hline
\end{tabular}

manpower productivity in the agricultural sector is far from the desired range. Figure 5 shows that the average total manpower productivity in the three climatic regions in the agricultural sector is different from the average total manpower productivity in the desired range of thermal comfort.

\section{Discussion}

The main aim of this study was to investigate the effect of workplace climate on labor productivity index in the agricultural sector. One of the most important findings of this study is that there is a relationship between workplace climate variables, the degree of workload (metabolism), and the type of coverage of people working in different climatic regions with the level of manpower productivity because a significant population of the country's labor are active in various agricultural occupations. Comparison of the results of data analysis as occupational hazards in the outdoor workplaces and calculation of thermal comfort and manpower productivity indicators in three climatic regions of the country with the desired limits of

$\checkmark$ Three climatic regions $₫$ Thermal comfort range

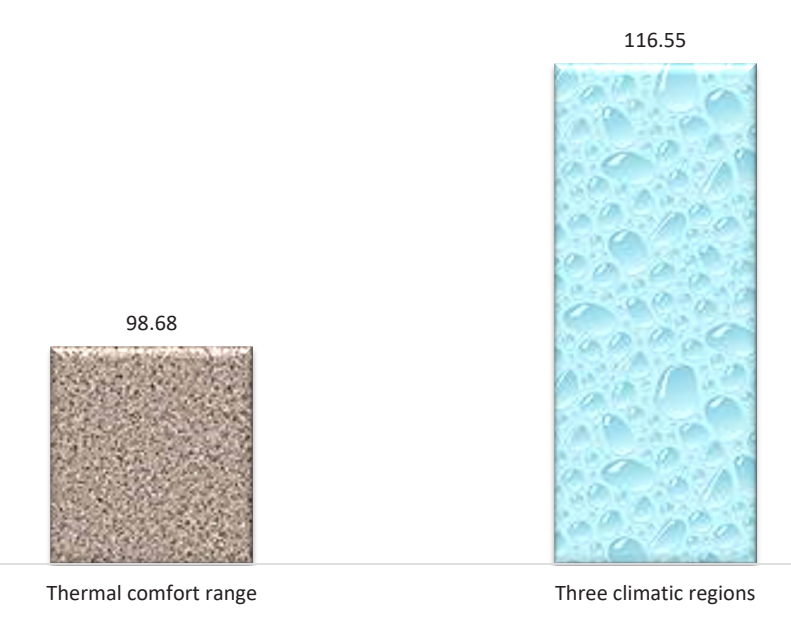

Figure 5. Comparison of the $\mathrm{P}$ index in three climate regions with thermal comfort range $(-1<\mathrm{PMV}<1)$ in the agricultural sector. thermal comfort (Table 2) and estimating the distance or proximity of the results with the measurement criteria in the scenarios of this study, which are shown in Figure 3, showed that the most effective factor in reducing labor productivity in cold climates for heavy jobs is the increase of air vapor pressure, which is inconsistent with the results of the study of Asadi et al, in the construction sector. This discrepancy can be due to climate change at the time of the present study compared to the time of their study (in two different decades) and their different (indoor) workplace (34). In a study by Heal and Park on thermal stress and the direct impact of climate change, it was found that increasing temperatures may increase labor productivity in cold regions (21), because the increased average annual temperature and the average radiant temperature are consistent with the increase in productivity in light and medium occupations.

The results in hot reigns of this study showed that all three environmental factors $\left(t_{a}, t_{r}, p_{a}\right)$ have a great impact on deviating from the desired criterion; in other words, reducing the productivity index at all three levels of workload and these results are supported by other studies $(7,18)$. Singh et al found that at temperatures above $35^{\circ} \mathrm{C}$, workers' health and productivity decreased and at $40^{\circ} \mathrm{C}$ in heavy workload jobs, the level of productivity reduces to one-third that may affect the agricultural economy of the area (35). The results of the studies by Kjellstrom et al, (31) and Quiller (36), using mixed linear effect models examining the impact of climate change on farmers' productivity, showed a relationship between increasing WBGT and decreasing productivity. There are significant economic effects of being exposed to excessive heat, which is consistent with the findings of the present study. Another analytical study estimated that the decline in labor productivity in the United States is due to the reduction in working time during the warmer months in terms of economic losses (37). Therefore, these studies show that reductions in human capacity for physical activity is likely to result in significant losses of work capacity due to the increase in the duration and intensity of the hot season $(31,38)$. The findings of this study in mild regions 
also showed that the most effective climate factor in the workplace is the trend of changes in air vapor pressure. The other two factors of the climate of the region $\left(R^{2}=0.8\right)$, did not show a significant effect on the labor productivity index $\left(\mathrm{R}^{2}=0.2\right)$, which is consistent with the results of the study of Asadi et al (34). Finally, the results showed that the PMV index has a significant relationship with the $\mathrm{P}$ index in all three climatic regions $(P=0.001)$. According to a study by Akbari et al, on 181 workers in the automotive assembly industry in two seasons of summer and winter, the relationship between heat strain and manpower productivity, was different, which can be the reason for the difference in the findings related to the use of PMV index influencing individual factors measuring the type of work of individuals (workload) in addition to environmental factors (39). Therefore, according to the findings, in heavy activities where the level of metabolism increases, and due to limitations such as different physiological readiness of workers and their adaptation to the weather conditions of the workplace, the type of clothing should be considered to improve the physical conditions in all three climatic regions. Despite other effective parameters on changes in labor productivity such as managerial factors, sociopsychological factors, cultural factors, economic factors, personality traits, and education, many reasons show that environmental conditions, including climate conditions, play a significant role in reducing or increasing the productivity of human resources (40).

\section{Conclusion}

According to the findings of the present study, PMV index has a significant relationship with $\mathrm{P}$ index in all three climatic regions, but the type of relationship based on the impact of environmental variables can be positive or negative. The average labor productivity index in agriculture was different from the desired amount of thermal comfort and of the NPO. As a result, due to climate change, the implementation of workplace climate control programs in the agricultural sector, which in turn will improve the performance of manpower, seems necessary to achieve economic goals.

\section{Acknowledgements}

Authors gratefully acknowledge the support from the Meteorological Organization and the NPO and the Statistics Center of Iran. Also, this study is a part of MSc thesis by Amini and supported by Ahvaz Jundishapur University of Medical Sciences (Grant No. U-98226).

\section{Ethical issues}

The study was approved by the Ethics Committee of Ahvaz Jundishapur University of Medical Sciences (Ethical code: IR.AJUMS.REC.1398.719).

\section{Competing interests}

The authors declare that they have no conflict of interests.
Authors' contributions

BFD, MA, and LIG prepared data and performed model runs. $\mathrm{BFD}, \mathrm{MA}, \mathrm{HR}$, and LIG designed the study, interpreted the results, and wrote the manuscript.

\section{References}

1. Statistical center of Iran. Statistical Yearbook of Iran; 2016. Available from: https://irandataportal.syr.edu/socioeconomic-data/statistical-yearbook.

2. Kjellstrom T, Holmer I, Lemke B. Workplace heat stress, health and productivity - an increasing challenge for low and middle-income countries during climate change. Glob Health Action 2009; 2. doi: 10.3402/gha.v2i0.2047.

3. Fahed AK, Ozkaymak M, Ahmed S. Impacts of heat exposure on workers' health and performance at steel plant in Turkey. Engineering Science and Technology, an International Journal 2018; 21(4): 745-52. doi: 10.1016/j. jestch.2018.05.005.

4. NASA. National Aeronautic and Space Administration Report: Climate Change and Global Warming, NASA, Washington, DC, USA; 2016. Available from: https://www. nasa.gov/feature/goddard/2016/climate-trends-continueto-break-records.

5. Ortiz LE, González JE, Horton R, Lin W, Wu W, Ramamurthy $\mathrm{P}$, et al. High-resolution projections of extreme heat in New York City. Int J Climatol 2019; 39(12): 4721-35. doi: 10.1002/joc.6102.

6. Parsons K. Human Thermal Environments: The Effects of Hot, Moderate, and Cold Environments on Human Health, Comfort, and Performance. 3th ed. USA: CRC Press; 2014.

7. Golbabaei F, Zakerian SA, Fouladi Dehaghi B, Ibrahimi Ghavamabadi L, Gharagozlou F, Mirzaei Aliabadi M, et al. Heat stress and physical capacity: A case study of semiprofes-sional footballers. Iran J Public Health 2014; 43(3): 355-61.

8. Mukherjee S. Climate Change: Implications for Human Resources in Informal Sector of Eastern India. In: Ergonomics for Rural Development; 2015. p. 174-8.

9. Chan AP, Yi W. Heat stress and its impacts on occupational health and performance. Indoor Built Enviro 2016; 25(1): 3-5. doi: 10.1177/1420326X15622724.

10. Kjellstrom T, Briggs D, Freyberg C, Lemke B, Otto M, Hyatt O. Heat, human performance, and occupational health: a key issue for the assessment of global climate change impacts. Annu Rev Public Health 2016; 37: 97-112. doi: 10.1146/annurev-publhealth-032315-021740.

11. Kjellstrom T, Freyberg C, Lemke B, Otto M, Briggs D. Estimating population heat exposure and impacts on working people in conjunction with climate change. Int J Biometeorol 2018; 62(3): 291-306. doi: 10.1007/s00484017-1407-0.

12. Hoegh-Guldberg O, Jacob D, Taylor M, Bindi M, Brown $\mathrm{S}$, Camilloni I, et al. Impacts of $1.5 \mathrm{C}$ global warming on natural and human systems. In: Intergovernmental Panel on Climate Change. Global warming of $1.5^{\circ} \mathrm{C}$. Geneva: IPCC; 2018.

13. Li M, Gu S, Bi P, Yang J, Liu Q. Heat waves and morbidity: current knowledge and further direction-a comprehensive literature review. Int J Environ Res Public Health 2015; 12(5):5256-83. doi: 10.3390/ijerph120505256. 
14. Odame EA, Li Y, Zheng S, Vaidyanathan A, Silver K. Assessing heat-related mortality risks among rural populations: a systematic review and meta-analysis of epidemiological evidence. Int J Environ Res Public Health 2018; 15(8): 1597. doi: 10.3390/ijerph15081597.

15. Yi W, Chan AP. Effects of heat stress on construction labor productivity in Hong Kong: a case study of rebar workers. Int J Environ Res Public Health 2017; 14(9): 1055. doi: 10.3390/ijerph14091055.

16. Burke M, Hsiang SM, Miguel E. Climate and conflict. Annu Rev Econom 2015; 7:577-617. doi: 10.1146/annureveconomics-080614-115430.

17. Day E, Fankhauser S, Kingsmill N, Costa H, Mavrogianni A. Upholding labour productivity under climate change: an assessment of adaptation options. Clim Policy 2019; 19(3): 367-85. doi: 10.1080/14693062.2018.1517640.

18. Zander KK, Botzen WJ, Oppermann E, Kjellstrom T, Garnett ST. Heat stress causes substantial labour productivity loss in Australia. Nat Clim Change 2015; 5(7): 647-51. doi: 10.1038/NCLIMATE2623.

19. Monazam Ismailpour M, Gol Babaei F, Khodayari F, Azam K. Survey of the productivity loss due to heat stress in different tasks of farmers in Darreh Shahr city. Journal of Health and Safety at Work 2015; 5(3): 74-63. [In Persian].

20. Fouladi Dehghi, B, Abedini, SM, Karimpour S, Ahmadi Angali K. Interactive effect of noise and heat on maximal aerobic capacity (vo2 max) in students of ahvaz jundishapur university of medical sciences. Journal of Health and Safety at Work 2019; 9(3), 191-99. [In Persian].

21. Heal G, Park J. Temperature stress and the direct impact of climate change: a review of an emerging literature. Rev Environ Econ Policy 2016; 10(2): 1-17. doi: 10.1093/reep/ rew007.

22. Hoegh-Guldberg O, Jacob D, Taylor M, Guillén Bolaños T, Bindi M, Brown S, et al. The human imperative of stabilizing global climate change at 1.5 C. Science 2019; 365(6459): eaaw6974. doi: 10.1126/science.aaw6974.

23. Mora C, Dousset B, Caldwell IR, Powell FE, Geronimo RC, Bielecki CR, et al. Global risk of deadly heat. Nat Clim Change 2017; 7(7): 501-06. doi: 10.1038/nclimate3322.

24. Meteorological Organization of Iran. Analyze data and provide meteorological statistics and information. [cited 2019 Mar 23] Available from: http://irimo.ir/far/services/ general_content/19462. [In Persian]

25. National Iranian Productivity Organization. Available from: https://www.npo.gov.ir/training-courses-held/itemid/121. [In Persian]

26. Dyvia HA, Arif C. Analysis of thermal comfort with predicted mean vote (PMV) index using artificial neural network. IOP Conf Ser Earth Environ Sci 2021; 622: 012019. Doi:10.1088/1755-1315/622/1/012019.

27. Owen MS. 2009 ASHRAE Handbook: Fundamentals. USA: American Society of Heating, Refrigeration and AirConditioning Engineers; 2009.
28. International Organization for Standardization. Ergonomics of the thermal environment--Estimation of thermal insulation and water vapor resistance of a clothing ensemble. [cited 2019 Mar 11] Available from: https://www. iso.org/standard/39257.html.

29. International Organization for Standardization. Ergonomics of the thermal environment-determination of metabolic rate. [cited 2019 Mar 11] Available from: https://www.iso. org/standard/34251.html.

30. International Organization for Standardization. Moderate thermal environments determination of the PMV and PPD indices and specification of the conditions for thermal comfort. [cited 2019 Mar 11] Available from: https://www. iso.org/standard/14567.html.

31. Kjellstrom T, Lemke B, Otto M. Mapping occupational heat exposure and effects in South-East Asia: ongoing time trends 1980-2009 and future estimates to 2050. Ind Health 2013; 51(10): 56-67. doi: 10.2486/indhealth.2012-0174.

32. Mohamed S, Srinavin K. Forecasting labor productivity changes in construction using the PMV index. Int J Ind Ergon 2005;35(4):345-51. doi: 10.1016/j.ergon.2004.09.008.

33. Raziei T. Köppen-Geiger climate classification of Iran and investigation of its changes during 20th century. Journal of the Earth and Space Physics 2017; 43(2): 419-39. doi: 10.22059/jesphys.2017.58916. [In Persian].

34. Asadi SH, Amini Fard A, Baqerpour M. Predicting changes in labor productivity in the construction sector using the average index of projected votes. Thirds International Conference on Management, Economics and Humanities; 2016 Sep 9; Iran: Georgian International Academy of Sciences; 2016.

35. Singh S, Hanna EG, Kjellstrom T. Working in Australia's heat: Health promotion concerns for health and productivity. Health Promot Int 2013; 30(2): 239-50. doi: 10.1093/heapro/dat027.

36. Quiller G. Heat stress, heat strain, and productivity in Washington State tree fruit harvesters [dissertation]. Washington: University of Washington; 2016.

37. Hsiang S, Kopp R, Jina A, Delgado M, Rising J, Mohan S, et al. American climate prospectus: economic Risks in the United States. USA: Rhodium Group; 2014.

38. Langkulsen U, Vichit-Vadakan N, Taptagaporn S. Health impact of climate change on occupational health and productivity in Thailand. Glob. Health Action 2010; 3. doi: 10.3402/gha.v3i0.5607.

39. Akbari J, Dehghan H, Azmoon H. Relationship between Heat strain and Human productivity in automotive assembly industry. Journal of Health System Research 2013; 9(9): 939-50. [In Persian].

40. Daghigh R, Sopian K. Effective ventilation parameters and thermal comfort study of air-conditioned offices. American Journal of Applied Sciences 2009; 6(5): 943-51. doi.org/10.3844/ajassp.2009.943.951. 